\title{
Prognostic significance of the preoperative serum levels of soluble form of endoglin in gastric cancer patients
}

\author{
Gomceli $\mathrm{I}^{1}$, Tez $\mathrm{M}^{2}$, Bostanci EB ${ }^{1}$, Kemik AS ${ }^{3}$, Demiriz B ${ }^{2}$, Akoglu $\mathrm{M}^{1}$ \\ Turkiye Yuksek Ihtisas Education and Research Hospital, Department of Gastroenterologic Surgery, Turkey. \\ mesuttez@yahoo.com
}

\begin{abstract}
Background: Gastric cancer is the second commonest cause of cancer-associated deaths in the world. Its molecular markers can be useful not only for the diagnostic pursuit but also for prognostic purposes. Endoglin was proposed as a marker of neovascularization in solid malignancies. A circulating form of endoglin is referred to as soluble endoglin (sol-end). The purpose of this study was to investigate the clinical importance of serum level of soluble form of sol-end in gastric cancer patients.

Materials and methods: Serum levels of sol-end were measured in 69 healthy controls and in 60 gastric adenocarcinoma patients with ELISA and serum levels of sol-end were compared with clinicopathological features and outcomes in gastric cancer patients.

Results: Serum levels of sol-end in gastric adenocancer patients were significantly higher than in control patients $(p<0.001)$. The serum levels of sol-end did not differ relative to clinical and pathologic criteria.

Conclusion: Presented data suggest that serum levels of sol-end do not seem to be a valuable tool in the assessment of gastric cancer prognosis (Tab. 1, Ref. 11). Full Text in PDF www.elis.sk.

Key words: endoglin, gastric cancer, prognosis.
\end{abstract}

Cancer is still a major public health problem worldwide. According to the International Gastric Cancer Society, more than 800.000 people are affected by gastric cancer every year, and up to 650,000 people have succumbed to gastric cancer. It is likely that in 2020 gastric cancer will increase by $10 \%$ in the developing countries (1-3).

One of the recently described substances important for angiogenesis is endoglin. Endoglin, also known as CD105, is a receptor for transforming growth factor- $\beta 1$ molecule, which binds preferentially to the activated endothelial cells participating in tumor angiogenesis, i.e. with weak or negative expression in vascular endothelium of normal tissues. Endoglin is induced by hypoxia. Endoglin assessed in gastric cancer tissues using immunohistochemistry was shown to correlate with newly formed blood vessels. Therefore it is very useful for assessment of neo-angiogenesis of malignant neoplasms $(4,5)$. Endoglin is expressed not only on cell surface, since its soluble form can be detected also in blood $(4,6)$. But, there are no sufficient data on the prognostic significance of serum level of soluble form of endoglin (sol-end) levels in gastric cancer patients.

In the present study, we assessed a possible role for preoperative serum level of sol-end as a potent predictor of prognosis in gastric cancer patients.

${ }^{1}$ Turkiye Yuksek Ihtisas Education and Research Hospital, Department of Gastroenterologic Surgery, Turkey, ${ }^{2}$ Ankara Numune Education and Research Hospital, Department of General Surgery, Turkey, and ${ }^{3}$ Istanbul University Cerrahpasa Medical Faculty, Department of Biochemistry, Turkey Address for correspondence: M. Tez, MD, 5. cadde 10/3 Bahcelievler, Ankara, Turkey.

Phone: +90.5324160669 , Fax: +90.3123061443

\section{Material and method}

Sixty consecutive patients with gastric adenocancer were enrolled in this study. The diagnoses in all patients were confirmed by histopathologic examination of their gastric resection specimens. Informed written consent was obtained before patient enrollment. This study has been approved by the institutional review board of Turkiye Yuksek Ihtisas Education and Research Hospital. Patients under the age of 18 , those with history of malignant disease, patients with synchronous tumor, patients with gastric tumor except adenocarcinoma, and patients who had received chemotherapy or radiation therapy before current surgical therapy were excluded from the study.

Surgery consisted of subtotal or total gastrectomy and D2 (i.e., extended) lymph-node dissection in all patients, except in cases with peritoneal or distant metastasis. Serial sections from paraffinembedded tissue blocks were obtained from gastric tumor tissues and used for histological diagnosis. Microdissected areas were assessed by an expert pathologist to estimate the status of perineural and vascular invasion, depth of tumor invasion, lymph-node metastasis and histological grading. The American Joint Committee on Cancer (AJCC), TNM Staging Classification of the Stomach (7th ed., 2010) was used for staging the tumor.

Control blood samples were obtained from 60 individuals who visited health examination clinics with minimal gastritis or normal appearance of the gastric mucosa on endoscopic examination. Blood samples were collected before malignancies were treated surgically. Samples were allowed to clot, and serum was obtained after sample centrifugation. Serum samples were stored frozen at $-20^{\circ} \mathrm{C}$. Repeated thawing and freezing of samples was 
avoided. Soluble form of endoglin in serum was assessed by sandwich ELISA using diagnostic kit manufactured by R\&D Systems (USA). The standard range of this kit is from 0.15 to $10 \mathrm{ng} / \mathrm{ml}$ and the minimum detectable dose is $0.007 \mathrm{ng} / \mathrm{ml}$.

\section{Statistical analysis}

SPSS for Windows 11.5 (Chi. Il., USA) was used for statistical analysis. Descriptive statistics were presented as mean \pm standard deviation. The demographic characteristics of patients and controls were compared using the $\chi 2$ square test and Student's $t$ test. Shapiro-Wilk test was used for assessing normality. Gaussian distribution of data for serum levels of sol-end in study subjects and differences in serum levels of sol-end were compared using Student's t test and one-way ANOVA test when appropriate. Correlations were evaluated using the Pearson correlation test. The survival probabilities were calculated using the Kaplan-Meier method. Differences between two groups were determined using the log-rank test. The influence of each significant predictor identified by log rank test was assessed by multivariate analysis using Cox's proportional hazards model. Significance was presumed at $\mathrm{p}<0.05$.

\section{Results}

There were $38(55.07 \%)$ male and 31 (44.93\%) female individuals in the control group with mean age of 55 (43-68). Serum endoglin levels were detectable in all healthy controls. The mean serum level of sol-end in healthy controls was $13.72 \pm 3.44$ $\mathrm{ng} / \mathrm{mL}$. There was no significant difference in serum level of solend between the male and female controls (Males: $13.67 \pm 17 \mathrm{ng} /$ $\mathrm{mL}$ and females: $13.86 \pm 3.10 \mathrm{ng} / \mathrm{mL}$ respectively, $\mathrm{p}=0.493)$. No correlation was found between serum levels of sol-end and age $(\mathrm{r}=0.084 ; \mathrm{p}=0.497)$.

After serum investigation of the patients with gastric adenocancer, endoglin was detectable in all individuals. Serum levels of solend in gastric adenocancer patients were significantly higher than those in healthy controls $(62.76 \pm 17.06 \mathrm{ng} / \mathrm{mL}$ versus $13.72 \pm 3.44$ $\mathrm{ng} / \mathrm{mL}$, respectively; $\mathrm{p}<0.001)$.

The relationship between serum levels of sol-end and clinicopathologic variables of gastric cancer were evaluated (Tab. 1). The serum levels of sol-end did not differ significantly with histopathologic grade, tumor size, tumor-node-metastasis (TNM) stage, tumor localization, lymph node metastases, positive lymph node ratio, perivascular invasion, perineural invasion, age and sex.

Univariate analysis showed the TNM stage $(\mathrm{p}=0.006)$, and ratio of metastatic lymph nodes to retrieved lymph nodes $(p=0.002)$ invasion to be significant factors affecting the overall survival. Multivariate regression analysis showed the TNM stage (hazard ratio, 6.65 ; 95\% CI, 2.14-20.41; $\mathrm{p}=0.003$ ), to be a single significant independent factor for overall survival.

\section{Discussion}

Endoglin, a receptor for transforming growth factor $\beta 1$ and $\beta 3$ is expressed predominantly on newly formed microvessels.
Tab. 1. The relationship between serum levels of soluble form of endoglin and clinicopathologic variables in gastric cancer patients.

\begin{tabular}{|c|c|c|c|}
\hline \multicolumn{4}{|l|}{ Variables } \\
\hline & $\mathbf{n}$ & $\begin{array}{c}\text { Endoglin, ng/mL } \\
\text { Mean } \pm \text { SD }\end{array}$ & $\mathbf{p}$ \\
\hline \multicolumn{4}{|l|}{ Age, $y$} \\
\hline$<50$ & 9 & $65.1 \pm 16.9$ & 0.912 \\
\hline $50-60$ & 12 & $62.7 \pm 18.1$ & \\
\hline $60<$ & 39 & $62.2 \pm 17.2$ & \\
\hline \multicolumn{4}{|l|}{ Sex } \\
\hline Male & 40 & $61.4 \pm 17.7$ & 0.424 \\
\hline Female & 20 & $65.4 \pm 23.1$ & \\
\hline \multicolumn{4}{|l|}{ Tumor localization } \\
\hline Cardia & 25 & $69.8 \pm 25.4$ & 0.719 \\
\hline Corpus & 7 & $73.4 \pm 28.8$ & \\
\hline Antrum & 28 & $73.3 \pm 21.8$ & \\
\hline \multicolumn{4}{|l|}{ Differentiation } \\
\hline Good & 9 & $67.5 \pm 17.6$ & 0.164 \\
\hline Moderate & 12 & $69.6 \pm 17.4$ & \\
\hline Poor & 39 & $59.5 \pm 16.37$ & \\
\hline \multicolumn{4}{|l|}{ Tumor size } \\
\hline$\leq 4 \mathrm{~cm}$ & 15 & $62.15 \pm 19.9$ & 0.480 \\
\hline $4 \mathrm{~cm}<$ & 39 & $61.85 \pm 16.7$ & \\
\hline \multicolumn{4}{|l|}{ Lymph node metastases (N) } \\
\hline 0 & 11 & $67.1 \pm 19.5$ & 0.204 \\
\hline I & 10 & $53.5 \pm 14.1$ & \\
\hline II & 17 & $65.8 \pm 17.7$ & \\
\hline III & 22 & $60.7 \pm 16.5$ & \\
\hline \multicolumn{4}{|l|}{ Positive lymph node ratio (\%) } \\
\hline $0(0)$ & 10 & $67.1 \pm 19.5$ & 0.158 \\
\hline $1(1-9)$ & 11 & $54.3 \pm 14.1$ & \\
\hline $2(10-25)$ & 13 & $67.2 \pm 17.3$ & \\
\hline $3(26<)$ & 26 & $61.2 \pm 17.1$ & \\
\hline \multicolumn{4}{|l|}{ TNM Stage } \\
\hline I/II(Early gastric carcinoma) & 17 & $59.9 \pm 17.9$ & 0.652 \\
\hline III / IV(late gastric carcinoma) & 43 & $63.9 \pm 16.8$ & \\
\hline \multicolumn{4}{|l|}{ Perineural invasion } \\
\hline Positive & 46 & $60.3 \pm 17.1$ & 0.162 \\
\hline Negative & 9 & $69.3 \pm 15.8$ & \\
\hline \multicolumn{4}{|l|}{ Vascular invasion } \\
\hline Positive & 46 & $60.4 \pm 17.2$ & 0.199 \\
\hline Negative & 9 & $68.9 \pm 15.5$ & \\
\hline
\end{tabular}

This modulation of endothelial -mesenchymal signaling is crucial for enhancing the proliferation and angiogenesis. Endoglin is also claimed to be involved in such phenomena as cell adhesion and migration (4). So far, most research studies on endoglin have focused on its role in angiogenesis and vascular remodeling. However, recent data have emerged suggesting that changes in endoglin expression in tumor cells contribute to the deregulation of TGF- $\beta$-dependent and-independent signaling pathways and malignant progression (7).

Only a handful of studies have reported the expression of endoglin in neoplastic cells of primary tumors. In prostate cancer, endoglin was detected in epithelial cells of both prostatic intraepithelial neoplasia and malignant areas (4). Endoglin expression is down-regulated in both primary esophageal squamous cell carcinomas and cell lines, and overexpression of endoglin in esophageal squamous cell carcinomas cells led to reduced invasiveness and tumorigenicity (8). Endoglin expression in breast tumor cells suppresses the invasion and metastasis, and correlates with improved 
$566-568$

clinical outcome (9). Endoglin was also found to be expressed by tumor cells in Ewing sarcoma and melanoma. Endoglin expression in these two types of cancer correlated with tumor cell plasticity and participates in the formation of vascular-like structures (10). On the other hand; the strong expression of endoglin indicated a poor prognosis in gastric cancer (5). The correlation of VEGF/ endoglin expression with the clinicopathological parameters of gastric cancer showed that the high expression of VEGF/endoglin was correlated only with lymph node metastasis (5). In mentioned study, the 10-year survival rate was $27.77 \%$ for patients with high VEGF/ endoglin-expressing tumors, which was significantly lower than the rate among patients with lower VEGF/ endoglin expressing tumors. Endoglin expression emerged as not independent variables of adverse prognostic significance. As seen, the prognostic significance of endoglin expression varies depending on the type of cancer.

The extracellular domain of membrane-bound endoglin can be proteolytically cleaved, releasing a circulating form of endoglin named soluble endoglin. Increased levels of sol-end are linked to the pathogenesis of severe vascular diseases such as systemic sclerosis and pre-eclampsia (4).

Soluble endoglin has been reported to rise in breast cancer patients who developed metastases, as compared to both normal controls and cancer patients without distant spread (11). Plasma sol-end level in prostate cancer has a predictive value for metastasis to the pelvic lymph nodes (7). High levels of sol- end are also present in myeloid malignancies that are characterized by a high cellular proliferation rate (7). Nonetheless, other reports on esophageal and ovarian tumors failed to find sol-end levels as a valuable marker in the assessment of cancer spread (4).

Mysliwiec et al and his colleagues investigated the serum and plasma endoglin levels in patients with gastric cancer. Twenty-six patients with gastric cancer were included in mentioned study. The authors did not find a difference between plasma and serum levels of endoglin. Also, authors did not find any significant correlations between endoglin in plasma or in serum and any clinical or pathological parameters (4). We achieved similar results in our study. In our study, serum levels of sol-end in patients with gastric cancer were higher than those in controls. However; high levels of solend had no relationship with clinical pathological variables and prognosis. The difference between the prognostic importance of serum levels of sol-end and tissue endoglin expression is a matter to be investigated. In conclusion, there is no prognostic significance of serum levels of sol-end in gastric cancer patients.

\section{References}

1. Jemal A, Siegel R, Ward E et al. Cancer statistics, 2009. CA Cancer J Clin 2009; 59: 225-249.

2. Crew KD, Neugut AI. Epidemiology of gastric cancer. World J Gastroenterol 2006; 12: 354-362.

3. Brenner H, Rothenbacher D, Arndt V. Epidemiology of stomach cancer. Methods Biol 2009; 472: 467-477.

4. Mysliwiec P, Pawlak K, Bandurski R, Kedra B. Soluble angiogenesis markers in gastric tumor patients. Folia Histochem Cytobiol 2009; 47: 81-86.

5. Nikiteas NI, Tzanakis N, Theodoropoulos G, Atsaves V, Christoni $\mathbf{Z}$, Karakitsos P et al. Vascular endothelial growth factor and endoglin (CD-105) in gastric cancer. Gastric Cancer 2007; 10: 12-17.

6. Takahashi N, Kawanishi-Tabata R, Haba A, Tabata M, Haruta Y, Tsai $\mathbf{H}$ et al. Association of serum endoglin with metastasis in patients with colorectal, breast, and other solid tumors, and suppressive effect of chemotherapy on the serum endoglin. Clin Cancer Res 2001; 7: 524-532.

7. Pérez-Gómez E, Del Castillo G, Juan Francisco S, López-Novoa JM, Bernabéu C, Quintanilla M. The role of the TGF- $\beta$ coreceptor endoglin in cancer. Sci World 2010; 10: 2367-2384.

8. Wong VC, Chan PL, Bernabeu C, Law S, Wang LD, Li JL et al. Identification of an invasion and tumor-suppressing gene, Endoglin (ENG), silenced by both epigenetic inactivation and allelic loss in esophageal squamous cell carcinoma. Int J Cancer 2008; 123: 2816-2823.

9. Henry LA, Johnson DA, Sarrió D, Lee S, Quinlan PR, Crook T et al. Endoglin expression in breast tumor cells suppresses invasion and metastasis and correlates with improved clinical outcome. Oncogene 2011; 30: 1046-1058.

10. Pardali E, van der Schaft DW, Wiercinska E, Gorter A, Hogendoorn PC, Griffioen AW et al. Critical role of endoglin in tumor cell plasticity of Ewing sarcoma and melanoma. Oncogene 2011; 30: 334-345.

11. Li C, Guo B, Wilson PB, Stewart A, Byrne G, Bundred N et al. Plasma levels of soluble CD105 correlate with metastasis in patients with breast cancer. Int J Cancer 2000; 89: 122-126. 